\title{
SOME SUFFICIENT CONDITIONS FOR FIXED POINTS OF MULTIVALUED NONEXPANSIVE MAPPINGS IN BANACH SPACES
}

\author{
XI WANG, CHIPING ZHANG AND YUNAN CUI
}

Abstract. In this paper, we show some sufficient conditions on a Banach space $X$ concerning the generalized von Neumann-Jordan constant, the coefficient $R(1, X)$ and the coefficient of weak orthogonality, which imply the existence of fixed points for multivalued nonexpansive mappings.

Mathematics subject classification (2010): 47H10, 46B20.

Keywords and phrases: Multivalued nonexpansive mapping, fixed point, generalized von NeumannJordan constant, generalized García-Falset coefficient, the coefficient of weak orthogonality.

\section{REFERENCES}

[1] T. D. BENAVIDES, A geometrical coefficient implying the fixed point property and stability results, Houston J. Math. 22, 4 (1996), 835-849.

[2] T. D. BENAVIDES AND B. GAVIRA, The fixed point property for multivalued nonexpansive mappings, J. Math. Anal. Appl. 328, 2 (2007), 1471-1483.

[3] T. D. BenaVides And B. GAVIRA, Does Kirk's theorem hold for multivalued nonexpansive mappings?, Fixed Point Theory Appl. 2010, 2 (2010), 546-761.

[4] T. D. BENAVIDES AND P. LoRENZO, Asymptotic centers and fixed points for multivalued nonexpansive mappings, Ann. Univ. Mariae Curie-Skłodowska Sect. A, 58 (2004), 37-45.

[5] J. A. Clarkson, The von neumann-jordan constant for the lebesgue space, Ann. of Math. 38, 1 (1937), 114-115.

[6] Y. Cui, W. HuAng, H. HudziK And R. KACZMAREK, Generalized von Neumann-Jordan constant and its relationship to the fixed point property, Fixed Point Theory Appl. 2015, 1 (2015), 1-11.

[7] S. Dhompongsa, A. Kaewcharoen and A. Kaewkhao, The Domínguez-Lorenzo condition and multivalued nonexpansive mappings, Nonlinear Anal. 64, 5 (2006), 958-970.

[8] S. Dhompongsa, T. D. Benavides, A. Kaewcharoen, A. Kaewkhao and B. Panyanak, The Jordan-von Neumann constant and fixed points for multivalued nonexpansive mappings, J. Math. Anal. Appl. 320, 2 (2006), 916-927.

[9] B. GAVIRA, Some geometric conditions which imply the fixed point property for multivalued nonexpansive mappings, J. Math. Anal. Appl. 339, 1 (2008), 680-690.

[10] A. JimÉnEZ-MELAdo AND E. LlORENS-FusTER, The fixed point property for some uniformly nonsquare Banach spaces, B. Unione Mat. Ital. 10, 3 (1996), 587-595.

[11] A. KAEW KAO, The James constant, the Jordan-von Neumann constant weak orthogonality and fixed points for multivalued mappings, J. Math. Anal. Appl. 333, 2 (2007), 950-958.

[12] W. A. KIRK AND S. MASSA, Remarks on asymptotic and Chebyshev centers, Houston J. Math. 16, 3 (1990), 357-364.

[13] T. C. LIM, Afixed point theorem for multivalued nonexpansive mappings in a uniformly convex Banach space, Bull. Amer. Math. Soc. 80, 1974 (1974), 1123-1126.

[14] S. B. NADler, JR., Multivalued contraction mappings, Messenger Math 30, 2 (1969), 475-488.

[15] X. WANG, Y. CUI AND C. ZHANG, The generalized von Neumann-Jordan constant and normal structure in Banach spaces, Ann. Funct. Anal. 6, 4 (2015), 206-214. 